\title{
Diagnosis and Management of Clinical Chorioamnionitis
}

\author{
Alan T. N. Tita, MD, PhDa and William W. Andrews, PhD, MD \\ a Assistant Professor of Obstetrics and Gynecology, Division of Maternal-Fetal Medicine, School \\ of Medicine, University of Alabama at Birmingham \\ b Charles E. Flowers Professor and Chairman, Department of Obstetrics and Gynecology, School \\ of Medicine, University of Alabama at Birmingham
}

\begin{abstract}
Chorioamnionitis is a common complication of pregnancy associated with significant maternal, perinatal, and long-term adverse outcomes. Adverse maternal outcomes include postpartum infections and sepsis while adverse infant outcomes include stillbirth, premature birth, neonatal sepsis, chronic lung disease and brain injury leading to cerebral palsy and other neurodevelopmental disabilities. Research in the last two decades has expanded our understanding of the mechanistic links between intraamniotic infection and preterm delivery as well as morbidities of preterm and term infants. Recent and ongoing clinical research into better methods for diagnosing, treating and preventing chorioamnionitis is likely to have a substantial impact on short and long-term outcomes in the neonate.
\end{abstract}

\section{Keywords}

Chorioamnionitis; infection; pregnancy; management

\section{Definition}

Chorioamnionitis or intraamniotic infection is an acute inflammation of the membranes and chorion of the placenta, typically due to ascending polymicrobial bacterial infection in the setting of membrane rupture. Chorioamnionitis can occur with intact membranes, and this appears to be especially common for the very small fastidious genital mycoplasmas such as Ureaplasma species and Mycoplasma hominis, found in the lower genital tract of over 70\% of women [1]. Only rarely is hematogeneous spread implicated in chorioamnionitis, as occurs with Listeria monocytogenes [2]. When characteristic clinical signs are present, the condition is referred to as clinical chorioamnionitis or clinical intraamniotic infection. Although there is significant overlap between clinical and histologic chorioamnionitis, the latter is a more common diagnosis based on pathologic findings on microscopic examination of the placenta that encompasses clinically unapparent (sub-clinical) chorioamnionitis as well as clinical chorioamnionitis. Funisitis, also a histopathologic diagnosis, is the extension of infection or inflammation to the umbilical cord. Overall the definition of chorioamnionitis

${ }^{\text {a } C o r r e s p o n d i n g ~ a u t h o r ~ f o r ~ p r o o f ~ a n d ~ r e p r i n t s: ~ D r . ~ A l a n ~ T . ~ N . ~ T i t a ~(a l a n . t i t a @ o b g y n . u a b . e d u) . ~ A d d r e s s ~(c o r r e s p o n d i n g ~ a u t h o r ~ a n d ~}$ coauthor), Department of Obstetrics and Gynecology, University of Alabama at Birmingham, $61919^{\text {th }}$ South, Birmingham, AL 3524, Tel: 205934 9616, Fax: 2059754375.

b ${ }_{\text {Co-author: Dr. William W. Andrews (William.andrews@obgyn.uab.edu) }}$

Publisher's Disclaimer: This is a PDF file of an unedited manuscript that has been accepted for publication. As a service to our customers we are providing this early version of the manuscript. The manuscript will undergo copyediting, typesetting, and review of the resulting proof before it is published in its final citable form. Please note that during the production process errors may be discovered which could affect the content, and all legal disclaimers that apply to the journal pertain. 
varies according to key diagnostic criteria, which can be clinical (presence of typical clinical findings), microbiologic (culture of microbes from appropriately collected amniotic fluid or chorioamnion) or histopathologic (microscopic evidence of infection or inflammation on examination of the placenta or chorioamnionic specimens).

\section{Epidemiology (incidence and risk factors)}

Overall, $1-4 \%$ of all births in the US are complicated by chorioamnionitis [2]; however, the frequency of chorioamnionitis varies markedly by diagnostic criteria, specific risk factors and gestational age [3-7]. Chorioamnionitis (clinical and histologic combined), complicates as many as $40-70 \%$ of preterm births with premature membrane rupture or spontaneous labor [8] and $1-13 \%$ of term births [9-11]. Twelve percent of primary cesarean births at term involve clinical chorioamnionitis, with the most common indication for cesarean in these cases being failure to progress usually after membrane rupture [12].

Multiple studies have reported risk factors for chorioamnionitis, including longer duration of membrane rupture, prolonged labor, nulliparity, African American ethnicity, internal monitoring of labor, multiple vaginal exams, meconium-stained amniotic fluid, smoking, alcohol or drug abuse, immune-compromised states, epidural anesthesia, colonization with group B streptococcus, bacterial vaginosis, sexually transmissible genital infections and vaginal colonization with ureaplasma [3-7,13-18]. A strong association between untreated GBS bacteriuria and chorioamnionitis may reflect the high concentration of GBS in the genital tract [19]. After adjusting for potential confounding variables and depending on the specific confounders considered, some of the risk factors for chorioamnionitis identified in older studies no longer demonstrate an association in recent studies. Select factors independently associated with chorioamnionitis and their strength of association are summarized in Table 1 [3-7,13-17]. Contrary to most obstetric conditions, chorioamnionitis in a previous pregnancy may not be associated with an increased risk of chorioamnionitis in a subsequent pregnancy [20]. Although PPROM is a major risk factor for clinical chorioamnionitis, it is noteworthy that together with preterm labor, PPROM frequently is the consequence of sub-clinical chorioamanionitis [21].

\section{Mechanisms of chorioamnionitis and its associated complications}

The pathogenesis of chorioamnionitis is marked by the passage of infectious organisms to the chorioamnion and/or umbilical cord of the placenta (Figures 1 and 2)[21-22]. This passage occurs most commonly by retrograde or ascending infection from the lower genital tract (cervix and vagina) (Figure 1). Hematogenous/transplacental passage and iatrogenic infection complicating amniocentesis or chorionic villous sampling are less common routes of infection. Anterograde infection from the peritoneum via the fallopian tubes has also been postulated [22]. The presence of infectious agents in the chorioamnion engenders a maternal and fetal inflammatory response characterized by the release of a combination of proinflammatory and inhibitory cytokines and chemokines in the maternal and fetal compartments (Figure 2). The inflammatory response may produce clinical chorioamnionitis and/or lead to prostaglandin release, ripening of the cervix, membrane injury and labor at term or premature birth at earlier gestational ages. Aside from the risk of direct fetal infection and sepsis, the fetal inflammatory response may induce cerebral white matter injury, which may result in cerebral palsy and other short and long-term neurological deficits (Figure 2).

Host defense mechanisms preventing intraamniotic infection remain poorly elucidated, but specific local host factors likely play an important role. The cervical mucous plug as well as the placenta and membranes provide a barrier to infection of the amniotic fluid and fetus. 
Peroxide-producing lactobacilli in the birth canal may induce changes in the flora that impair the virulence of pathogenic organisms.

\section{Clinical Signs and Symptoms}

The key clinical findings associated with clinical chorioamnionitis include fever, uterine fundal tenderness, maternal tachycardia (>100/min), fetal tachycardia (>160/min) and purulent or foul amniotic fluid $[2,4]$.

Maternal fever is the most important clinical sign of chorioamnionitis. Temperature $>$ $100.4^{\circ} \mathrm{F}$ is considered abnormal in pregnancy. While isolated low-grade fever $\left(<101^{\circ} \mathrm{F}\right)$ may be transient in labor, fever $>100.4^{\circ} \mathrm{F}$ persisting more than $1 \mathrm{~h}$ or any fever $\geq 101^{\circ} \mathrm{F}$ warrants evaluation and appropriate intervention. Fever is present in $95-100 \%$ of cases of clinical chorioamnionitis and typically is required for the diagnosis (see below). Fever in the setting of epidural anesthesia, particularly among nulliparous women with prolonged labor (so called epidural fever) is often encountered and poses a diagnostic quagmire vis-à-vis chorioamnionitis [23]. This is because i) in addition to fever, the two conditions share other major risk factors (low parity and prolonged labor), ii) epidural anesthesia masks signs of chorioamnionitis such as fundal tenderness, and iii) medications given during epidural anesthesia may induce maternal or fetal tachycardia and therefore confound the diagnosis of chorioamnionitis [24]. The exact mechanism of epidural fever is unknown, but it is thought to be the result of epidural sympathetic blockade of thermoregulatory processes such as sweating [24]. In one study, maternal fever was more common among the epidural group when placental inflammation was present (35\% vs. $17 \%$ ) but not in the absence of inflammation (11\% vs. 9\%). This suggests that the pathologic basis for epidural fever is chorioamnionitis [23]. In sum, the concept of epidural fever remains controversial and warrants additional studies.

Maternal tachycardia (>100 BPM) and fetal tachycardia (>160 BPM) occur frequently in chorioamnionitis, being reported in $50-80 \%$ and $40-70 \%$ of cases respectively. Tachycardia may be present in the absence of chorioamnionitis and requires careful assessment for alternative etiologies. Medications such as ephedrine, antihistamines, and beta agonists may raise maternal or fetal heart rate. However, the combination of maternal fever and maternal and/or fetal tachycardia are strongly suggestive of intrauterine infection and should be treated accordingly.

Aside from the objective measurements of maternal fever and tachycardia, other signs of chorioamnionitis are highly subjective. Uterine fundal tenderness and a foul odor to the amniotic fluid are reported in only $4-25 \%$ of cases of chorioamnionitis [4]. Fundal tenderness is difficult to interpret in the context of the pain of labor and may be masked by analgesics including epidural or confounded by the pain associated with placental abruption. Purulence or foul odor of amniotic fluid are more likely to be present with severe or prolonged infection and may be organism-specific, but in any case may or may not be appreciated by clinicians.

Chorioamnionitis that is subclinical by definition does not present the above clinical signs but may manifest as preterm labor or, even more commonly, as preterm premature rupture of membranes (PPROM). In addition, premature ROM at term (membrane rupture at $\geq 37$ weeks gestation but prior to onset of uterine contractions), which occurs in $8 \%$ or less of term births, is associated with an increased risk of chorioamnionitis [25] 


\section{Diagnosis of chorioamnionitis}

\section{a) Clinical signs and symptoms}

As suggested by the name, clinical chorioamnionitis is diagnosed solely based on clinical signs since access to uncontaminated amniotic fluid or placenta for culture is invasive and usually avoided. Typically, the presence of fever $>100.4$ is required in addition to two other signs (uterine tenderness, maternal or fetal tachycardia and foul/purulent amniotic fluid) $[2,4,26]$. Individual clinical criteria have variable sensitivity and low specificity for chorioamnionitis (see table 2). Because of the low specificity of clinical findings a consideration of other potential sources of fever and other causes of clinical symptoms is essential for the diagnosis of chorioamnionitis [26]. In the absence of other etiologies the combination of 3 clinical criteria provides a highly accurate diagnosis of chorioamnionitis. The presence of risk factors of chorioamnionitis, especially membrane rupture, further strengthens the diagnosis.

\section{b) Laboratory tests}

Findings from laboratory or bedside testing may aid in ruling in or out the diagnosis of chorioamnionitis, particularly when the clinical signs and symptoms are equivocal (Table 2) [2,27-32]. Recent research on proteomic analysis for diagnosing intraamniotic infection is discussed elsewhere in this series.

i) CBC—Maternal leucocytosis (variously defined as WBC $>12,000 / \mathrm{mm} 3$ or $>15,000 /$ $\mathrm{mm} 3$ ) or the presence of a left shift or bandemia (>9\%) often supports the diagnosis of chorioamnionitis. Leucocytosis is reported in approximately $70-90 \%$ of cases of clinical chorioamnionitis. However, isolated leucocytosis in the absence of other signs or symptoms is of limited value since it may be induced by several other conditions including labor and steroid use. Therefore routine monitoring of CBC in high-risk women (e.g., with preterm premature membrane rupture) in the absence of clinical signs of chorioamnionitis is not useful.

ii) Other blood tests-Other laboratory parameters including high levels of C-reactive protein (CRP), lipopolysacharide binding protein (LBP), soluble intercellular adhesion molecule 1 (SICAM 1) and interleukin 6 have been associated with a higher risk of chorioamnionitis in the setting of PPROM or preterm delivery [33-37]. However, their utility for the diagnosis or prediction of choriamnionitis as part of routine clinical practice is not established.

iii) Amniotic fluid testing-Tests on amniotic fluid, usually obtained by amniocentesis, have been used for the diagnosis of chorioamnionitis (table 2) [26,30-32]. Culture of amniotic fluid is the most reliable test but is of limited utility since culture results may not be available for up to 3 days. In addition, because of the invasive nature of the procedure, amniocentesis is not performed in the majority of cases, which occur during labor. Some clinicians use amniocentesis to confirm clinically suspected chorioamnionitis in order to determine whether preterm delivery is warranted (thus avoiding "iatrogenic prematurity"), Amniocentesis is also used in some centers to identify subclinical chorioamnionitis in women with spontaneous preterm labor and preterm membrane rupture at early gestational ages. However, the value of this practice has recently been questioned [38].

ORGANISMS CAUSING CHORIOAMNIONITIS: Chorioamnionitis is a polymicrobial infection most often due to ascending genital microbes [2,39]; over $65 \%$ of positive amniotic fluid cultures involve two or more organisms. The genital mycoplasmas, Ureaplasma urealyticum and Mycoplasma hominis (genital mycoplasmas), constitute the 
most frequent microbes occurring in up to $47 \%$ and $30 \%$ respectively of cases of cultureconfirmed chorioamnionitis [39-40]. Their role in the pathogenesis of chorioamnionitis and neonatal complications, once controversial, is now increasingly accepted [41]. These fastidious organisms provoke a robust inflammatory reaction affecting both maternal and fetal compartments, particularly in preterm gestations [40-42]. They are commonly isolated from amniotic fluid in the setting of preterm birth or premature membrane rupture with or without clinical chorioamnionitis [41]. While genital mycoplasmas are found in the lower genital tract (vagina and/or cervix) of over $70 \%$ of women, their presence in the upper genital tract (uterus or fallopian tubes) and chorioamnion of pregnant women is rare $(<5 \%)$ in the absence of labor or membrane rupture [41,43].

Other common isolates in women with chorioamnionitis include anaerobes such as Gardnerella vaginalis (25\%) and bacteroides (30\%), as well as aerobes including Group B streptococcus (GBS, 15\%) and gram-negative rods including Escherichia coli (8\%)[39]. These organisms are commonly part of the vaginal flora (especially in women with bacterial vaginosis ) or the enteric flora (E. coli and other gram negative rods, enterococci and anaerobes). An entity of "aerobic vaginitis", (distinguished from bacterial vaginosis in that it represents a strong host immune response to aerobic vaginal flora typically comprised of GBS and E. coli) has been associated with ascending chorioamnionitis, PPROM and preterm birth [44]. Occasionally chorioamnionitis is the result of hematogenous spread of bacterial or viral infection to the placenta. Listeria monocytogenes infection of the fetus, which presents a pattern of both early onset and late onset neonatal sepsis similar to GBS, is presumed to be due to a hematogenous route rather than an ascending infection [45]. More research is needed to clarify the significance of individual microbes and their potential interactions in the pathogenesis of chorioamnionitis. For clinical decision-making and management, however, knowing the exact organisms involved in chorioamnionitis is not generally useful.

Other tests on amniotic fluid (table 2) are limited in their overall predictive abilities for chorioamnionitis although the interleukin 6 and matrix metalloproteinase are more promising because of higher sensitivity and specificity [30-32]. The use of vaginal pool fluid after premature membrane rupture for these assessments (e.g. glucose level) is still rudimentary and warrants further investigation [46].

iv) Placental and umbilical cord pathology-Histologic chorioamnionitis captures sub-clinical as well as clinical chorioamnionitis, thus it is not surprising that overall histologic chorioamnionitis at term is up to 3 times as frequent as clinical chorioamnionitis confirmed by amniotic fluid culture [47]. This is in part because cultures for genital mycoplasmas, the most common organisms associated with chorioamnionitis, are not very sensitive. Subclinical chorioamnionitis and non-infectious inflammation also contribute to this discrepancy. Histologic chorioamnionitis is defined by the presence of acute histologic changes on examination of the amnionic membrane and chorion of the placenta and funisitis is characterized by leukocyte infiltration of the umbilical vessel wall or Wharton's jelly [48]. Acute histological changes are typically characterized either according to the number of polymorphonuclear leukocytes per high power field or by detailed systems of staging/ grading involving documentation of polymorphonuclear leukocyte location, density, and degeneration to estimate intensity and progression of chorioamnionitis [49]. Consequently, depending on the criteria used and maternal characteristics (including ethnicity and type of labor), the prevalence of chorioamnionitis based on placental pathology varies widely. Using varying thresholds of polymorphonuclear leukocytes per high power field, the prevalence ranged from $7-85 \%$ in term and 4-63\% in preterm deliveries in one study (49]). Overall, histologic chorioamnionitis is a sensitive (83-100\%) but not a specific (23-52\%) predictor of chorioamnionitis when the diagnosis is based on culture-positive amniotic fluid [50]. On 
the other hand, clinical chorioamnionitis is not uniformly confirmed on pathologic evaluation. In one study only $62 \%$ of women with clinically diagnosed chorioamnionitis had histologic evidence of chorioamnionitis, leading to the speculation that non-inflammatory causes such as epidural fever and abruption accounted for some of the cases [51]. For these reasons, placental pathology should be performed to confirm suspected chorioamnionitis even if amniotic fluid culture is negative. The pathologic finding of funisitis (inflammation of the umbilical cord) is even more concerning than chorioamnionitis alone as it represents a fetal response to infection. While chorioamnionitis is present in nearly all cases of funisitis, funisitis is present in only up to $60 \%$ of cases of chorioamnionitis [52].

\section{c) Differential diagnosis}

Several other conditions should be considered in the differential diagnosis of chorioamnionitis. In the intrapartum patient with an epidural and low-grade fever without tachycardia (maternal or fetal) or other clinical signs of intrauterine inflammation, epiduralassociated fever is a strong consideration. Extrauterine infections can cause fever and abdominal pain, either during or in absence of labor, including urinary tract infection (pyelonephritis), influenza, appendicitis, and pneumonia. Non-infectious conditions associated with abdominal pain (usually in absence of fever) include thrombophlebitis, round ligament pain, colitis, connective tissue disorders and placental abruption.

\section{Complications of chorioamnionitis}

Clinical chorioamnionitis carries adverse consequences affecting both the woman and her infant (Figure 2).

\section{Maternal complications}

Chorioamnionitis leads to a 2 to 3 -fold increased risk for cesarean delivery and 2 to 4 -fold increase in endomyometritis, wound infection, pelvic abscess, bacteremia and postpartum hemorrhage [12,53-56]. The increase in postpartum hemorrhage appears to be due to dysfunctional uterine muscle contractions as a result of inflammation [54-55]. Ten percent of women with chorioamnionitis have positive blood cultures (bacteremia) most commonly involving GBS and E. coli [2]. Fortunately, however, septic shock, disseminated intravascular coagululation, adult respiratory distress syndrome and maternal death are only rarely encountered[57].

i) Fetal complications-Fetal exposure to infection may lead to fetal death, neonatal sepsis and numerous other postnatal complications (Figure 2). The fetal response to infection - termed the Fetal Inflammatory Response Syndrome (FIRS) - may cause or aggravate some of these complications. FIRS is the fetal counterpart of the systemic inflammatory response syndrome (SIRS). Since clinical parameters analogous to those defining SIRS are difficult to ascertain in the fetus, FIRS was originally defined by elevation of cord blood IL-6 in the setting of preterm labor and PPROM [58-59] but can also occur in term gestations. The histopathologic hallmarks of FIRS are funisitis and chorionic vasculitis [60]. FIRS is now recognized to represent the fetal immune response to infection or injury mediated by the release of cytokines and chemokines such as interleukins, TNF-alpha, Creactive protein, and matrix melloproteinases [59]. FIRS has also been linked to preterm labor culminating in perinatal death (Figure 2) and is associated, particularly among preterm neonates, with multi-organ injury, including chronic lung disease, periventricular leucomalacia and cerebral palsy, [62-64] Although FIRS may occur in the setting of noninfectious inflammation, its magnitude tends to be significantly more robust with documented infection [61] Although somewhat controversial, fetal exposure to genital 
mycoplasmas (U. urealyticum and M. hominis) has been associated with a fetal and neonatal systemic inflammatory response syndrome, pneumonia and BPD [65-68].

ii) Neonatal and long-term complications-The neonate exposed to intrauterine infection and inflammation may show adverse effects at or shortly after birth. Adverse outcomes may include perinatal death, asphyxia, early onset neonatal sepsis, septic shock, pneumonia, intraventricular hemorrhage (IVH), cerebral white matter damage, and longterm disability including cerebral palsy [69-74]. In one study of term infants, neonatal pneumonia, sepsis and perinatal death did not occur in the absence of chorioamnionitis but occurred, respectively, in $4 \%, 8 \%$ and $2 \%$ of term deliveries associated with chorioamnionitis. In this study, respiratory distress occurred in $2 \%$ of term infants in absence of chorioamnionitis and 20\% when chorioamnionitis was present [69]. Preterm infants have an even higher rate of complications of chorioamnionitis than term infants, including perinatal death ( 25 vs. $6 \%$ preterm vs. term), neonatal sepsis ( 28 vs. $6 \%$ ), pneumonia ( 20 vs. $3 \%$ ), grades 3 or 4 IVH (24 vs. $8 \%$ ) and respiratory distress (62 vs. $35 \%$ ) [71]. Overall, chorioamnionitis is associated with up to $40 \%$ of cases of early-onset neonatal sepsis. Chorioamnionitis is also well-established as a risk factor for long-term neurodevelopmental disability especially when it occurs prior to term [2,75-79]. In term and near-term infants it is associated with a 4-fold increase in the frequency of cerebral palsy [76-77]

\section{Management}

Prompt initiation of antibiotic therapy is essential to prevent both maternal and fetal complications in the setting of clinical chorioamnionitis [2]. Time -to-delivery after institution of antibiotic therapy has been shown to not affect morbidities; therefore cesarean section to expedite delivery is not indicated for chorioamnionitis unless there are other obstetric indications $[12,53,78]$.

\section{Antibiotics}

Evidence from randomized trials and observational studies demonstrate that immediate intrapartum use of broad-spectrum antibiotics significantly reduces maternal and fetal complications of chorioamnionitis [79-83]. The frequency of neonatal sepsis is reduced by up to $80 \%$ with intrapartum antibiotic treatment [80-81]. In a small randomized trial, neonatal sepsis occurred in none of 26 deliveries with intrapartum use of antibiotics compared to $21 \%$ of the 19 infants treated immediately postpartum [79].

The optimal antibiotic regimen for treatment of clinical chorioamnionitis has not been wellstudied and current recommendations are based largely on clinical consensus [83]. Intravenous administration of ampicillin every 6 hours and gentamicin every 8-24 hours until delivery is the typical regimen [83-84]. If cesarean delivery is performed, clindamycin every 8 hours (or metronidazole) is often added for anaerobic coverage. Optimal treatment should also include administration of a single intravenous additional dose of antibiotics after delivery ( $<5 \%$ failure rate) [85]; further oral antibiotic treatment is not beneficial in most cases [86].

Interestingly, although genital mycoplasmas are the most commonly isolated organisms associated with chorioamnionitis, the standard antibiotic regimens used for clinical chorioamnionitis do not provide optimal coverage against these organisms. Clindamycin does provide coverage against mycoplasma hominis but none of the 3 standard antibiotics is effective against ureaplasma species which is the most common group associated with infection. The standard regimen effectively treats maternal infection (>95\% success rate) and reduces neonatal sepsis, and there are currently no published trials suggesting that 
specific coverage against ureaplasma (with macrolide antibiotics) provides additional benefits in the setting of chorioamnionitis.

i) Supportive measures-Supportive measures include the use of antipyretics (acetaminophen). This is particularly important during the intrapartum period since fetal acidosis in the setting of fever has been associated with a marked increase in the incidence of neonatal encephalopathy [87]. Maternal fever even in the absence of documented fetal acidosis is associated with adverse neonatal outcomes, particularly neonatal encephalopathy, though it is unclear to what extent the etiology of the fever rather than the fever itself is causative [88]. Treating intrapartum fever with antipyretics may also be helpful in reducing fetal tachycardia thereby avoiding the tendency to perform cesarean for a non-reassuring fetal status.

\section{Prevention}

Expectant management of preterm premature rupture of membranes (PPROM) is a major cause of clinical chorioamnionitis - up to $70 \%$ of those who subsequently develop contractions or labor have chorioamnionitis [8]. Prophylactic or "latency" antibiotics, typically ampicillin and erythromycin, have been demonstrated in large clinical trials (ORACLE I and II) and systematic reviews to confer benefits including reduction in a primary composite of neonatal death, chronic lung disease or major cerebral abnormality on ultrasound. Antibiotics have also been shown to reduce the incidence of clinical or pathologic chorioamnionitis and neonatal sepsis and to prolong time-to-delivery among women with preterm membrane rupture managed expectantly but not among those in active preterm labor with intact membranes (in whom maternal infection was reduced) [89-91]. Amoxicillin/clavulanate antibiotic combinations should be avoided for this indication because of a potential association with an increased risk of necrotizing enterocolitis [89-91]. Furthermore, in the ORACLE II trial the use antibiotics for women with spontaneous preterm labor (SPTL) with intact membranes was associated with an unexpected increase in cerebral palsy in infants [92-93]. The findings were limited by potential selection bias (only $70 \%$ followed up) and use of maternal report to ascertain outcomes (no direct examination). The authors speculated that the findings could be due to chance or to maintenance of the fetus in a milieu with suppressed (not eradicated) subclinical infection given the low dose and oral route of antibiotics [92-93]. Another large trial conducted by the National Institutes of Health and Human Development Maternal-Fetal Medicine Units (NICHD MFMU) network in the late 1990s suggested a benefit of erythromycin in reducing adverse perinatal outcomes including perinatal death and morbidity as well as maternal infection [94]. No long-term follow-up data from this study has been reported. The usual standard in the US therefore remains the administration of broad spectrum antibiotics typically involving a macrolide (erythromycin or azithromycin) and ampicillin for 7-10 days via intravenous (2 days) followed by oral routes [95]. Induction of labor and delivery for PPROM after 34 weeks' gestation is recommended because, compared to expectant management, expeditious delivery is associated with reduced maternal infection and need for neonatal intensive care without any increase in perinatal morbidity and mortality [25,96-97]. However there is currently wide variation in practice and additional trials are ongoing to firmly establish the benefit of induction of labor prior to 37 weeks in cases of PPROM [25,98-100]. In the setting of prolonged membrane rupture ( $>18$ hours) at term, prophylactic antibiotics are not indicated if the mother is not colonized with GBS; however the CDC recommends starting GBS prophylaxis if GBS status is unknown [101]. In one randomized trial the use of intrapartum prophylactic antibiotics (ampicillin/sulbactam) for meconium-stained fluid was associated with a reduction in the risk of chorioamnionitis [102] 


\section{Summary}

Chorioamnionitis is a common infection of pregnancy, typically occurring in the setting of prolonged membrane rupture or labor. It may be diagnosed clinically based on signs such as maternal fever, microbiologically based on amniotic fluid culture obtained by amniocentesis, or by histopathologic examination of the placenta and umbilical cord. Chorioamnionitis is associated with postpartum maternal infections and potentially devastating fetal complications including premature birth, neonatal sepsis and cerebral palsy. The main preventative strategy is administration of antibiotics to women with preterm premature rupture of membranes which reduces the incidence of clinical chorioamnionitis, prolongs the time to delivery and improves neonatal outcomes. Optimal management of clinical chorioamnionitis includes antibiotic therapy and delivery. However, shortening the time between diagnosis and delivery by performance of cesarean section in the setting of broad spectrum antibiotic administration has been shown not to improve outcomes.

\section{Acknowledgments}

Dr. Tita was a Women's Reproductive Health Research (WRHR) Scholar supported by Grant No. 5K12, HD01258-09 from the NICHD, National Institutes of Health at the time of manuscript preparation.

\section{References}

1. Eschenbach DA. Ureaplasma urealyticum and premature birth. Clin Infect Dis 1993;17 (Suppl 1):S100-6. [PubMed: 8399898]

2. Gibbs RS, Duff P. Progress in pathogenesis and management of clinical intraamniotic infection. Am J Obstet Gynecol 1991;164:1317. [PubMed: 2035575]

3. Soper DE, Mayhall CG, Dalton HP. Risk factors for intraamniotic infection: a prospective epidemiologic study. Am J Obstet Gynecol 1989;161:562. [PubMed: 2782335]

4. Newton ER. Chorioamnionitis and intraamniotic infection. Clin Obstet Gynecol 1993;36:795. [PubMed: 8293582]

5. Newton ER, Prihoda TJ, Gibbs RS. Logistic regression analysis of risk factors for intra-amniotic infection. Obstet Gynecol 1989;73:571. [PubMed: 2927851]

6. Piper JM, Newton ER, Berkus MD, Peairs WA. Meconium: A marker for peripartum infection. Obstet Gynecol 1998;91:741. [PubMed: 9572222]

7. Tran SH, Caughey AB, Musci TJ. Meconium-stained amniotic fluid is associated with puerperal infections. Am J Obstet Gynecol 2003;189:746. [PubMed: 14526306]

8. Yoon BH, Romero R, Moon JB, et al. Clinical significance of intra-amniotic inflammation in patients with preterm labor and intact membranes. Am J Obstet Gynecol 2001;185:1130. [PubMed: 11717646]

9. Alexander JM, McIntire DM, Leveno KJ. Chorioamnionitis and the prognosis for term infants. Obstet Gynecol 1999;94(2):274-8. [PubMed: 10432142]

10. Seong HS, Lee SE, Kang JH, Romero R, Yoon BH. The frequency of microbial invasion of the amniotic cavity and histologic chorioamnionitis in women at term with intact membranes in the presence or absence of labor. Am J Obstet Gynecol 2008;199(4):375.e1-5. [PubMed: 18928978]

11. Blume HK, Li CI, Loch CM, Koepsell TD. Intrapartum fever and chorioamnionitis as risks for encephalopathy in term newborns: a case-control study. Dev Med Child Neurol 2008;50(1):19-24. [PubMed: 18173624]

12. Rouse DJ, Landon M, Leveno KJ, et al. The Maternal-Fetal Medicine Units cesarean registry: chorioamnionitis at term and its duration-relationship to outcomes. Am J Obstet Gynecol 2004;191:211. [PubMed: 15295368]

13. Soper DE, Mayhall CG, Froggatt JW. Characterization and control of intraamniotic infection in an urban teaching hospital. Am J Obstet Gynecol 1996;175(2):304-9. discussion 309-10. [PubMed: 8765246] 
14. Seaward PG, Hannah ME, Myhr TL, Farine D, Ohlsson A, Wang EE, Haque K, Weston JA, Hewson SA, Ohel G, Hodnett ED. International Multicentre Term Prelabor Rupture of Membranes Study: evaluation of predictors of clinical chorioamnionitis and postpartum fever in patients with prelabor rupture of membranes at term. Am J Obstet Gynecol 1997;177(5):1024-9. [PubMed: 9396886]

15. Rickert VI, Wiemann CM, Hankins GD, McKee JM, Berenson AB. Prevalence and risk factors of chorioamnionitis among adolescents. Obstet Gynecol 1998;92(2):254-7. [PubMed: 9699762]

16. Yancey MK, Duff P, Clark P, Kurtzer T, Frentzen BH, Kubilis P. Peripartum infection associated with vaginal group B streptococcal colonization. Obstet Gynecol 1994;84(5):816-9. [PubMed: 7936518]

17. Newton ER, Piper J, Peairs W. Bacterial vaginosis and intraamniotic infection. Am J Obstet Gynecol 1997;176(3):672-7. [PubMed: 9077627]

18. Abele-Horn M, Peters J, Genzel-Boroviczény O, Wolff C, Zimmermann A, Gottschling W. Vaginal Ureaplasma urealyticum colonization: influence on pregnancy outcome and neonatal morbidity. Infection 1997;25(5):286-91. [PubMed: 9334863]

19. Anderson BL, Simhan HN, Simons KM, Wiesenfeld HC. Untreated asymptomatic group B streptococcal bacteriuria early in pregnancy and chorioamnionitis at delivery. Am J Obstet Gynecol 2007;196(6):524.e1-5. [PubMed: 17547879]

20. Dinsmoor MJ, Gibbs RS. Previous intra-amniotic infection as a risk factor for subsequent peripartal uterine infections. Obstet Gynecol 1989;74(3 Pt 1):299-301. [PubMed: 2761903]

21. Goldenberg RL, Andrews WW, Hauth JC. Choriodecidual infection and preterm birth. Nutr Rev 2002;60(5 Pt 2):S19-25. [PubMed: 12035853]

22. Fahey JO. Clinical management of intra-amniotic infection and chorioamnionitis: a review of the literature. J Midwifery Womens Health 2008;53(3):227-35. [PubMed: 18455097]

23. Dashe JS, Rogers BB, McIntire DD, Leveno KJ. Epidural analgesia and intrapartum fever: placental findings. Obstet Gynecol 1999;93(3):341-4. [PubMed: 10074975]

24. Apantaku O, Mulik V. Maternal intra-partum fever. J Obstet Gynaecol 2007 Jan;27(1):12-5. [PubMed: 17365450]

25. ACOG Committee on Practice Bulletins-Obstetrics. ACOG Practice Bulletin No. 80: premature rupture of membranes. Clinical management guidelines for obstetrician-gynecologists. Obstet Gynecol 2007;109(4):1007-19. [PubMed: 17400872]

26. Riggs JW, Blanco JD. Pathophysiology, diagnosis, and management of intraamniotic infection. Semin Perinatol 1998;22(4):251-9. [PubMed: 9738989]

27. Gomez R, Ghezzi F, Romero R, Munoz H. Premature labor and intra-amniotic infection. Clinical aspects and role of the cytokines in diagnosis and pathophysiology. Clin Perinatol 1995;22:281. [PubMed: 7671540]

28. Harirah H, Donia SE, Hsu CD. Amniotic fluid matrix metalloproteinase-9 and interleukin-6 in predicting intra-amniotic infection. Obstet Gynecol 2002;99:80. [PubMed: 11777515]

29. Gauthier DW, Meyer WJ. Comparison of gram stain, leukocyte esterase activity, and amniotic fluid glucose concentration in predicting amniotic fluid culture results in preterm premature rupture of membranes. Am J Obstet Gynecol 1992;167:1092. [PubMed: 1384334]

30. Kim KW, Romero R, Park HS, Park CW, Shim SS, Jun JK, Yoon BH. A rapid matrix metalloproteinase- 8 bedside test for the detection of intraamniotic inflammation in women with preterm premature rupture of membranes. Am J Obstet Gynecol 2007;197(3):292.e1-5. [PubMed: 17826425]

31. Romero R, Yoon BH, Mazor M, Gomez R, Gonzalez R, Diamond MP, Baumann P, Araneda H, Kenney JS, Cotton DB, et al. A comparative study of the diagnostic performance of amniotic fluid glucose, white blood cell count, interleukin-6, and gram stain in the detection of microbial invasion in patients with preterm premature rupture of membranes. Am J Obstet Gynecol 1993;169(4):839-51. [PubMed: 7694463]

32. Hoskins IA, Marks F, Ordorica SA, Young BK. Leukocyte esterase activity in amniotic fluid: normal values during pregnancy. Am J Perinatol 1990;7(2):130-2. [PubMed: 2331274] 
33. Maeda K, Matsuzaki N, Fuke S, Mitsuda N, Shimoya K, Nakayama M, Suehara N, Aono T. Value of the maternal interleukin 6 level for determination of histologic chorioamnionitis in preterm delivery. Gynecol Obstet Invest 1997;43(4):225-31. [PubMed: 9194619]

34. Steinborn A, Sohn C, Scharf A, Geka F, Heger S, Kaufmann M. Serum intercellular adhesion molecule-1 levels and histologic chorioamnionitis. Obstet Gynecol 2000;95(5):671-6. [PubMed: 10775727]

35. Zou L, Zhang H, Zhu J, Zhu J. The value of the soluable intercellular adhesion molecule-1 levels in matermal serum for determination of occult chorioamnionitis in premature rupture of membranes. J Huazhong Univ Sci Technolog Med Sci 2004;24(2):154-7. [PubMed: 15315168]

36. Wu HC, Shen CM, Wu YY, Yuh YS, Kua KE. Subclinical histologic chorioamnionitis and related clinical and laboratory parameters in preterm deliveries. Pediatr Neonatol 2009;50(5):217-21. [PubMed: 19856865]

37. van de Laar R, van der Ham DP, Oei SG, Willekes C, Weiner CP, Mol BW. Accuracy of Creactive protein determination in predicting chorioamnionitis and neonatal infection in pregnant women with premature rupture of membranes: a systematic review. Eur J Obstet Gynecol Reprod Biol 2009;147(2):124-9. Epub 2009 Oct 12. [PubMed: 19819609]

38. Andrews WW, Cliver SP, Biasini F, Peralta-Carcelen AM, Rector R, Alriksson-Schmidt AI, FayePetersen O, Carlo W, Goldenberg R, Hauth JC. Early preterm birth: association between in utero exposure to acute inflammation and severe neurodevelopmental disability at 6 years of age. Am J Obstet Gynecol 2008;198(4):466.e1-466.e11. [PubMed: 18395043]

39. Sperling RS, Newton E, Gibbs RS. Intraamniotic infection in low-birth-weight infants. J Infect Dis 1988;157(1):113-7. [PubMed: 3335795]

40. Waites KB, Katz B, Schelonka RL. Mycoplasmas and ureaplasmas as neonatal pathogens. Clin Microbiol Rev 2005;18(4):757-89. [PubMed: 16223956]

41. Cassell GH, Waites KB, Watson HL, Crouse DT, Harasawa R. Ureaplasma urealyticum intrauterine infection: role in prematurity and disease in newborns. Clin Microbiol Rev 1993;6(1): 69-87. [PubMed: 8457981]

42. Yoon BH, Romero R, Park JS, Chang JW, Kim YA, Kim JC, Kim KS. Microbial invasion of the amniotic cavity with Ureaplasma urealyticum is associated with a robust host response in fetal, amniotic, and maternal compartments. Am J Obstet Gynecol 1998;179(5):1254-60. [PubMed: 9822511]

43. Witt A, Berger A, Gruber CJ, Petricevic L, Apfalter P, Worda C, Husslein P. Increased intrauterine frequency of Ureaplasma urealyticum in women with preterm labor and preterm premature rupture of the membranes and subsequent cesarean delivery. Am J Obstet Gynecol 2005;193(5):1663-9. [PubMed: 16260207]

44. Donders GG, Vereecken A, Bosmans E, Dekeersmaecker A, Salembier G, Spitz B. Definition of a type of abnormal vaginal flora that is distinct from bacterial vaginosis: aerobic vaginitis. BJOG 2002;109(1):34-43. [PubMed: 11845812]

45. Silver HM. Listeriosis during pregnancy. Obstet Gynecol Surv 1998;53(12):737-40. [PubMed: 9870235]

46. Buhimschi CS, Sfakianaki AK, Hamar BG, et al. A low vaginal "pool" amniotic fluid glucose measurement is a predictive but not a sensitive marker for infection in women with preterm premature rupture of membranes. Am J Obstet Gynecol 2006;194:309. [PubMed: 16458622]

47. Dong Y, St Clair PJ, Ramzy I, et al. A microbiologic and clinical study of placental inflammation at term. Obstet Gynecol 1987;70:175. [PubMed: 3601279]

48. Yoon BH, Romero R, Moon JB, Shim SS, Kim M, Kim G, Jun JK. Clinical significance of intraamniotic inflammation in patients with preterm labor and intact membranes. Am J Obstet Gynecol 2001;185(5):1130-6. [PubMed: 11717646]

49. Holzman C, Lin X, Senagore P, Chung H. Histologic chorioamnionitis and preterm delivery. Am J Epidemiol 2007;166(7):786-94. Epub 2007 Jul 11. [PubMed: 17625222]

50. Pettker CM, Buhimschi IA, Magloire LK, Sfakianaki AK, Hamar BD, Buhimschi CS. Value of placental microbial evaluation in diagnosing intra-amniotic infection. Obstet Gynecol 2007;109(3):739-49. [PubMed: 17329528] 
51. Smulian JC, Shen-Schwarz S, Vintzileos AM, et al. Clinical chorioamnionitis and histologic placental inflammation. Obstet Gynecol 1999;94:1000. [PubMed: 10576190]

52. Holcroft CJ, Askin FB, Patra A, Allen MC, Blakemore KJ, Graham EM. Are histopathologic chorioamnionitis and funisitis associated with metabolic acidosis in the preterm fetus? Am J Obstet Gynecol 2004 Dec;191(6):2010-5. [PubMed: 15592284]

53. Hauth JC, Gilstrap LC 3rd, Hankins GD, Connor KD. Term maternal and neonatal complications of acute chorioamnionitis. Obstet Gynecol 1985;66:59. [PubMed: 4011072]

54. Mark SP, Croughan-Minihane MS, Kilpatrick SJ. Chorioamnionitis and uterine function. Obstet Gynecol 2000;95:909.

55. Satin AJ, Maberry MC, Leveno KJ, Sherman ML. Chorioamnionitis: a harbinger of dystocia. Obstet Gynecol 1992;79:913. [PubMed: 1579312]

56. Newton ER, Schroeder BC, Knape KG, Bennett BL. Epidural analgesia and uterine function. Obstet Gynecol 1995;85:749. [PubMed: 7724107]

57. Moretti M, Sibai BM. Maternal and perinatal outcome of expectant management of premature rupture of membranes in the midtrimester. Am J Obstet Gynecol 1988 Aug;159(2):390-6. [PubMed: 3407697]

58. Gomez R, Romero R, Ghezzi F, Yoon BH, Mazor M, Berry SM. The fetal inflammatory response syndrome. Am J Obstet Gynecol 1998;179(1):194-202. [PubMed: 9704787]

59. Gotsch F, Romero R, Kusanovic JP, Mazaki-Tovi S, Pineles BL, Erez O, Espinoza J, Hassan SS. The fetal inflammatory response syndrome. Clin Obstet Gynecol 2007;50(3):652-83. [PubMed: 17762416]

60. Pacora P, Chaiworapongsa T, Maymon E, et al. Funisitis and chorionic vasculitis: the histological counterpart of the fetal inflammatory response syndrome. J Matern Fetal Neonatal Med 2002;11:18-25. [PubMed: 12380603]

61. Lee SE, Romero R, Jung H, Park CW, Park JS, Yoon BH. The intensity of the fetal inflammatory response in intraamniotic inflammation with and without microbial invasion of the amniotic cavity. Am J Obstet Gynecol 2007;197(3):294.e1-6. [PubMed: 17826426]

62. Yoon BH, Romero R, Kim KS, Park JS, Ki SH, Kim BI, Jun JK. A systemic fetal inflammatory response and the development of bronchopulmonary dysplasia. Am J Obstet Gynecol 1999;181(4): 773-9. [PubMed: 10521727]

63. Mittendorf R, Covert R, Montag AG, elMasri W, Muraskas J, Lee KS, Pryde PG. Special relationships between fetal inflammatory response syndrome and bronchopulmonary dysplasia in neonates. J Perinat Med 2005;33(5):428-34. [PubMed: 16238538]

64. Bashiri A, Burstein E, Mazor M. Cerebral palsy and fetal inflammatory response syndrome: a review. J Perinat Med 2006;34(1):5-12. [PubMed: 16489880]

65. Aaltonen R, Vahlberg T, Lehtonen L, Alanen A. Ureaplasma urealyticum: no independent role in the pathogenesis of bronchopulmonary dysplasia. Acta Obstet Gynecol Scand 2006;85(11):13549. [PubMed: 17091417]

66. Aaltonen R, Heikkinen J, Vahlberg T, Jensen JS, Alanen A. Local inflammatory response in choriodecidua induced by Ureaplasma urealyticum. BJOG 2007;114(11):1432-5. [PubMed: 17949381]

67. Goldenberg RL, Andrews WW, Goepfert AR, Faye-Petersen O, Cliver SP, Carlo WA, Hauth JC. The Alabama Preterm Birth Study: umbilical cord blood Ureaplasma urealyticum and Mycoplasma hominis cultures in very preterm newborn infants. Am J Obstet Gynecol 2008;198(1):43.e1-5. [PubMed: 18166302]

68. Jacobsson B, Aaltonen R, Rantakokko-Jalava K, Morken NH, Alanen A. Quantification of Ureaplasma urealyticum DNA in the amniotic fluid from patients in PTL and pPROM and its relation to inflammatory cytokine levels. Acta Obstet Gynecol Scand 2009;88(1):63-70. [PubMed: 19031281]

69. Yoder PR, Gibbs RS, Blanco JD, Castaneda YS. A prospective, controlled study of maternal and perinatal outcome after intra-amniotic infection at term. Am J Obstet Gynecol 1983;145:695. [PubMed: 6829656]

70. Alexander JM, McIntire DM, Leveno KJ. Chorioamnionitis and the prognosis for term infants. Obstet Gynecol 1999;94:274. [PubMed: 10432142] 
71. Morales WJ, Washington SR 3rd, Lazar AJ. The effect of chorioamnionitis on perinatal outcome in preterm gestation. J Perinatol 1987;7:105. [PubMed: 3505603]

72. Lau J, Magee F, Qiu Z, et al. Chorioamnionitis with a fetal inflammatory response is associated with higher neonatal mortality, morbidity, and resource use than chorioamnionitis displaying a maternal inflammatory response only. Am J Obstet Gynecol 2005;193:708. [PubMed: 16150264]

73. Aziz N, Cheng YW, Caughey AB. Neonatal outcomes in the setting of preterm premature rupture of membranes complicated by chorioamnionitis. J Matern Fetal Neonatal Med 2009:1.

74. Ramsey PS, Lieman JM, Brumfield CG, Carlo W. Chorioamnionitis increases neonatal morbidity in pregnancies complicated by preterm premature rupture of membranes. Am J Obstet Gynecol 2005;192:1162. [PubMed: 15846196]

75. Cornette L. Fetal and neonatal inflammatory response and adverse outcome. Semin Fetal Neonatal Med 2004;9:459. [PubMed: 15691784]

76. Wu YW, Escobar GJ, Grether JK, et al. Chorioamnionitis and cerebral palsy in term and near-term infants. JAMA 2003;290:2677. [PubMed: 14645309]

77. Nelson KB, Ellenberg JH. Antecedents of cerebral palsy. I. Univariate analysis of risks. Am J Dis Child 1985;139:1031. [PubMed: 4036890]

78. Gilstrap LC 3rd, Cox SM. Acute chorioamnionitis. Obstet Gynecol Clin North Am 1989;16:373. [PubMed: 2674804]

79. Gibbs RS, Dinsmoor MJ, Newton ER, Ramamurthy RS. A randomized trial of intrapartum versus immediate postpartum treatment of women with intra-amniotic infection. Obstet Gynecol 1988;72:823. [PubMed: 3186087]

80. Sperling RS, Ramamurthy RS, Gibbs RS. A comparison of intrapartum versus immediate postpartum treatment of intra-amniotic infection. Obstet Gynecol 1987;70:861. [PubMed: 3684121]

81. Gilstrap LC 3rd, Leveno KJ, Cox SM, Burris JS. Intrapartum treatment of acute chorioamnionitis: impact on neonatal sepsis. Am J Obstet Gynecol 1988;159:579. [PubMed: 3421256]

82. Maberry MC, Gilstrap LC 3rd. Intrapartum antibiotic therapy for suspected intraamniotic infection: impact on the fetus and neonate. Clin Obstet Gynecol 1991;34:345. [PubMed: 1868642]

83. Hopkins L, Smaill F. Antibiotic regimens for management of intraamniotic infection. Cochrane Database Syst Rev 2002:CD003254. [PubMed: 12137684]

84. Locksmith GJ, Chin A, Vu T, et al. High compared with standard gentamicin dosing for chorioamnionitis: a comparison of maternal and fetal serum drug levels. Obstet Gynecol 2005;105:473. [PubMed: 15738010]

85. Edwards RK, Duff P. Single additional dose postpartum therapy for women with chorioamniotis. Obstet Gynecol 2003;102:957. [PubMed: 14672470]

86. Dinsmoor MJ, Newton ER, Gibbs RS. A randomized, double-blind, placebo-controlled trial of oral antibiotic therapy following intravenous antibiotic therapy for postpartum endometritis. Obstet Gynecol 1991;77:60. [PubMed: 1984229]

87. Impey LW, Greenwood CE, Black RS, et al. The relationship between intrapartum maternal fever and neonatal acidosis as risk factors for neonatal encephalopathy. Am J Obstet Gynecol 2008;198:49. [PubMed: 18166304]

88. Impey L, Greenwood C, MacQuillan K, Reynolds M, Sheil O. Fever in labour and neonatal encephalopathy: a prospective cohort study. BJOG 2001;108(6):594-7. [PubMed: 11426893]

89. Kenyon SL, Taylor DJ, Tarnow-Mordi W. ORACLE Collaborative Group. Broad-spectrum antibiotics for preterm, prelabour rupture of fetal membranes: the ORACLE I randomised trial. ORACLE Collaborative Group. Lancet 2001;357(9261):979-88. [PubMed: 11293640]

90. Kenyon SL, Taylor DJ, Tarnow-Mordi W. ORACLE Collaborative Group. Broad-spectrum antibiotics for spontaneous preterm labour: the ORACLE II randomised trial. ORACLE Collaborative Group. Lancet 2001;357(9261):989-94. [PubMed: 11293641]

91. Kenyon S, Boulvain M, Neilson J. Antibiotics for preterm rupture of the membranes: a systematic review. Obstet Gynecol 2004;104(5 Pt 1):1051-7. [PubMed: 15516401]

92. Kenyon S, Pike K, Jones DR, et al. Childhood outcomes after prescription of antibiotics to pregnant women with preterm rupture of the membranes: 7-year follow-up of the ORACLE I trial. Lancet 2008;372:1310-1318. [PubMed: 18804274] 
93. Kenyon S, Pike K, Jones DR, et al. Childhood outcomes after prescription of antibiotics to pregnant women with spontaneous preterm labour: 7-year follow-up of the ORACLE II trial. Lancet 2008;372:1319-1327. [PubMed: 18804276]

94. Mercer BM, Miodovnik M, Thurnau GR, Goldenberg RL, Das AF, Ramsey RD, Rabello YA, Meis PJ, Moawad AH, Iams JD, Van Dorsten JP, Paul RH, Bottoms SF, Merenstein G, Thom EA, Roberts JM, McNellis D. Antibiotic therapy for reduction of infant morbidity after preterm premature rupture of the membranes. A randomized controlled trial. National Institute of Child Health and Human Development Maternal-Fetal Medicine Units Network. JAMA 1997;278(12): 989-95. [PubMed: 9307346]

95. American College of Obstetricians and Gynecologists. Practice bulletin number 47, October 2003: Prophylactic Antibiotics in Labor and Delivery. Obstet Gynecol 2003;102(4):875-82. [PubMed: 14551023]

96. Simhan HN, Canavan TP. Preterm premature rupture of membranes: diagnosis, evaluation and management strategies. BJOG 2005;112 (Suppl 1):32-7. [PubMed: 15715592]

97. Dare MR, Middleton P, Crowther CA, Flenady VJ, Varatharaju B. Planned early birth versus expectant management (waiting) for prelabour rupture of membranes at term (37 weeks or more). Cochrane Database Syst Rev 2006;(1):CD005302. [PubMed: 16437525]

98. Ramsey PS, Nuthalapaty FS, Lu G, Ramin S, Nuthalapaty ES, Ramin KD. Contemporary management of preterm premature rupture of membranes (PPROM): a survey of maternal-fetal medicine providers. Am J Obstet Gynecol 2004;191(4):1497-502. [PubMed: 15507990]

99. Morris JM, Roberts CL, Crowther CA, Buchanan SL, Henderson-Smart DJ, Salkeld G. Protocol for the immediate delivery versus expectant care of women with preterm prelabour rupture of the membranes close to term (PPROMT) Trial [ISRCTN44485060]. BMC Pregnancy Childbirth 2006;6:9. [PubMed: 16556323]

100. van der Ham DP, Nijhuis JG, Mol BW, van Beek JJ, Opmeer BC, Bijlenga D, Groenewout M, Arabin B, Bloemenkamp KW, van Wijngaarden WJ, Wouters MG, Pernet PJ, Porath MM, Molkenboer JF, Derks JB, Kars MM, Scheepers HC, Weinans MJ, Woiski MD, Wildschut HI, Willekes C. Induction of labour versus expectant management in women with preterm prelabour rupture of membranes between 34 and 37 weeks (the PPROMEXIL-trial). BMC Pregnancy Childbirth 2007;7:11. [PubMed: 17617892]

101. Centers for Disease Control and Prevention. Prevention of Perinatal Group B Streptococcal Disease. MMWR 2002;51(RR-11):16-18.

102. Adair CD, Ernest JM, Sanchez-Ramos L, Burrus DR, Boles ML, Veille JC. Meconium-stained amniotic fluid-associated infectious morbidity: a randomized, double-blind trial of ampicillinsulbactam prophylaxis. Obstet Gynecol 1996;88(2):216-20. [PubMed: 8692505] 


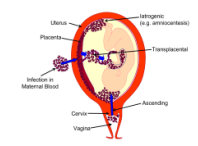

Figure 1.

Routes of chorioamnionitis/funisitis 


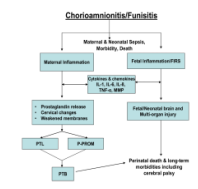

Figure 2.

Pathogenesis of Chorioamnionitis: Maternal and Fetal Response and Complications $\mathrm{IL}=$ Interleukin, $\mathrm{TNF}=$ Tumor Necrosis Factor, MMP=Matrix metalloproteinase, FIRS=Fetal Inflammatory Response Syndrome, PTB Preterm birth 
Table 1

Selected risk factors and their relative risks for chorioamnionitis,

\begin{tabular}{|l|l|l|}
\hline Risk factor & Relative risk & Reference(s) \\
\hline Prolonged membrane rupture (including PPROM) & & 13 \\
$\geq 12$ hours & 5.8 & 15 \\
$>18$ hours & 6.9 & \\
\hline Prolonged labor & 3.7 & 15 \\
Second stage > 2 hours & 4.0 & 14 \\
Active labor >12 hours & 2 to 5 & 13 14 \\
\hline Multiple digital exams with membrane rupture & 1.8 & 14 \\
$\geq 3$ exams & 1.7 to 7.2 & $14,16,19$ \\
\hline Nulliparity & 1.7 & 17 \\
\hline Group B streptococcus colonization & 7.9 & 15 \\
\hline Bacterial vaginosis & $1.4-2.3$ & 7,14 \\
\hline Alcohol and tobacco use & 2.0 & 13 \\
\hline Meconium-stained amniotic fluid & 4.1 & 15 \\
\hline Internal monitoring & & \\
\hline Epidural anesthesia & & 15 \\
\hline
\end{tabular}


Table 2

Clinical and amniotic fluid laboratory diagnosis of chorioamnionitis

\begin{tabular}{|l|l|l|}
\hline Test & Result suggesting chorioamnionitis & Comments \\
\hline Clinical parameters & & Generally non-specific [4] \\
\hline Fever & Temperature $>100.4$ twice or $>101$ once & $95-100$ sensitive [4] \\
\hline Maternal tachycardia & $>100 / \mathrm{min}$ & $50-80 \%$ sensitive \\
\hline Fetal tachycardia & $>160 /$ min & $40-70 \%$ sensitive \\
\hline Fundal tenderness & tenderness on palpation & $4-25 \%$ sensitive \\
\hline Vaginal discharge & Foul-smelling discharge & $5-22 \%$ sensitive \\
\hline Amniotic fluid parameters & & \\
\hline Culture & Microbial growth & Diagnostic gold-standard \\
\hline Gram stain & Bacteria or white blood cells $(>6 / \mathrm{HPF})$ & $24 \%$ sensitive, 99\% specific [31] \\
\hline Glucose level & $<15 \mathrm{mg} / \mathrm{dl}$ & Affected by maternal hyperglycemia $57 \%$ sensitive, 74\% specific \\
& & {$[31]$} \\
\hline Interleukin 6 & $>7.9 \mathrm{ng} / \mathrm{ml}$ & $81 \%$ sensitive, 75\% specific [31] \\
\hline Matrix Metalloproteinase & Positive result & $90 \%$ sensitive and $80 \%$ specific [30] \\
\hline White blood cell count & $>30 /$ cubic mm & $57 \%$ sensitive, 78\% specific [31] \\
\hline Leukocyte esterase & Positive (dipsticks) & $85-91 \%$ sensitive, 95-100\% specific [26,32] \\
\hline
\end{tabular}

